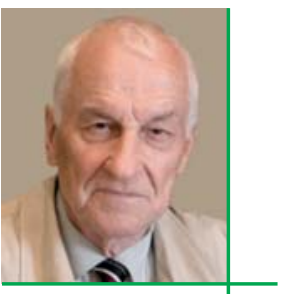

Куприенко П.И.

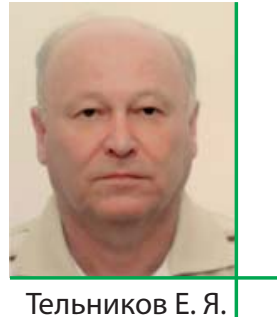

Тельников Е. Я.
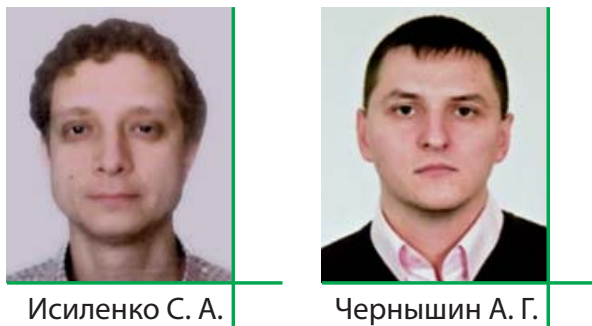

Чернышин А. Г.
Куприенко П. И., доктор технических наук, профессор кафедры ТКД, Киевский национальный университет строительства и архитектуры, г. Киев 03037,Воздухофлотский проспект 31,

凶tkd362@ukr.net $\%$ +38 (044) 520-01-13.

Тельников Е. Я., кандидат технических наук, старший научный сотрудник, Институт проблем материаловедения им.И.Н.Францевича НАН Украины, г. Киев 03680, ул. Кржижановского 3, 凶 evg.telnikov@ukr.net \% +38 (067) 600-01-46.

Исиленко С. А., аспирант кафедры ТКД,

Киевский национальный университет строительства и архитектуры,

г. Киев 03037,Воздухофлотский проспект 31,

凶tkd362@ukr.net +38 (044) 520-01-13.

Чернышин А. Г., директор ГП ИЦ «Сушка»,

ИТТФ НАНУ,

凶 chernyshin.a@agromat.ua ※ +38 (067) 490-22-86
P. Kuprienko, Doctor of Technical Sciences, Professor of the Department of TCD, Kyiv National University of Construction and Architecture,

Kiev 03037, 31 Vozduhoflotsky Prospect,

凶tkd362@ukr.net $\%$ +38 (044) 520-01-13.

E. Telnikov, Cand.Tech.Sci., Senior Researcher, Institute for Problems of

Materials Science named after I.N.Fantsevich NAS of Ukraine,

Kiev 03680, st. Krzhizhanovskogo 3,

凶 evg.telnikov@ukr.net \% +38 (067)600-01-46.

S. Isilenko, postgraduate student of the department of TKD, Kyiv National University of Construction and Architecture,

Kiev 03037, 31 Vozduhoflotsky Prospekt,

凶tkd362@ukr.net \% +38 (044) 520-01-13.

A. Chernyshin, Director of the State Enterprise "Sushka»,

ITTF NASU,

$凶$ chernyshin.a@agromat.ua $\approx+38(067) 490-22-86$

\title{
ТОЛСТОПЛЕНОЧНЫЕ НАГРЕВАТЕЛЬНЫЕ ЭЛЕМЕНТЫ: СВОЙСТВА, ИСПОЛЬЗОВАНИЕ, ТЕПЛОВАЯ ЭФФЕКТИВНОСТЬ, ИСПОЛЬЗОВАНИЕ В ЭЛЕКТРОТОВАРАХ
}

\section{ТОВСТОПЛІВКОВІ НАГРІВАЛЬНІ ЕЛЕМЕНТИ: ВЛАСТИВОСТІ, ВИКОРИСТАННЯ, ТЕПЛОВА ЕФЕКТИВНІСТЬ, ВИКОРИСТАННЯ В ЕЛЕКТРОТОВАРАХ}

\author{
THICK-FILM HEATING ELEMENT: PROPERTIES, USES, THERMAL EFFICIENCY, THE USE OF ELECTRICAL GOODS
}

Анотация. В статье рассматриваются толстопленочные нагревательные элементы, электрофизические свойства, особенности технологии изготовления, сферы использования в быту и промышленности. Приведен сравнительный расчет тепловой эффективности на примере электрических воздухонагревателей (калориферов).

Ключевые слова: толстопленочные нагревательные элементы, тепловая эффективность.

Анотація. У статті розглядаються товстоплівкові нагрівальні елементи, електрофізичні властивості, особливості технології виготовлення, сфери використання в побуті та промисловості. Наведено порівняльний розрахунок теплової ефективності на прикладі електричних повітронагрівачів (калориферів). Ключові слова: товстоплівкові нагрівальні елементи, теплова ефективність.

Annotation. In the article thick-film heating elements, electrophysical properties, features of manufacturing technology, spheres of use in everyday life and industry are considered. A comparative calculation of thermal efficiency is given for the example of electric air heaters (calorifiers).

Keywords: thick-film heating elements, thermal efficiency.

\section{Постановка проблемы}

В настоящее время промышленностью выпускается достаточно широкий ассортимент бытовых и промышленных электротоваров. В последние годы устройство электротоваров претерпевает существенные изменения благодаря широкому внедрению микроэлектроники и новейших нагревательных элементов (толстопленочных). Расширяется производство товаров с повышенными функциональными возможностями. Непрерывно совершенствуется ассортимент в направлении повышения их качества, увеличения продолжительности действия.

Рынок, в данный момент, не менее чем на 95 \%, насыщен нагревательными элементами на основе «нити накала», проволоки с высоким сопротивлением на основе которой выпускается большой ассортимент «ТЭНов». ТЕН представляет собой нихромовую спираль, вставленную в стальную трубку, наполненную кристаллической смесью магния. Такая система не является герметичной, и в процессе работы спираль окисляется и постепенно разрушается. Особенно ускорен этот процесс в ТЕНах, работающих при высоких температурах (800 ${ }^{\circ} \mathrm{C}$ и выше), что чаще всего достигается при отсутствии доста- точного теплосъема. Данный тип нагревательных элементов хоть и широко используется, имеет множество недостатков:

- непродолжительный срок службы;

малая площадь тепообмена;

в большинстве случаев - это трубка, что усложняет теплопередачу, например к плоским поверхностям; и т.д.

В виду всего этого все более актуальным становиться широкое внедрение толстопленочных (плоских) нагревательных элементов, которые значительно изменяют потребительские свойства привычных электрических устройств.

Разработкой материалов необходимых для производства толстопленочных нагревательных элементов (ТНЭ), технологией их производства, теплотехнические расчеты производит ГП ИЦ «Сушка» при ИТТФ НАНУ, а массовым производством ТНЭ и приборов на их основе на территории Украины занимается компания ООО «Агромат - Декор» и реализует их под TM «DEWEIT». 
TM «DEWEIT» - это бренд энергоэффективного теплового оборудования.

Все тепловое оборудование производится на основе уникальной технологии толстопленочных нагревательных элементов - современных заменителей ТЕНов, имеющих ряд преимуществ:

1. Повышенная надежность (от 40 тыс. часов работы).

2. Экономия электроэнергии до $40 \%$ по сравнению с ТЕНовыми аналогами.

3. Любая форма и мощность; возможность работы под любым напряжением.

4. Мощное инфракрасное излучение в «дружественном» для человека длинноволновом диапазоне (14 MKM).

5. Быстрый выход на рабочую температуру (в 2 раза быстрее ТЕНовых аналогов).

6. Безшумность, отсутствие свечения.

Все ТНЭ и приборы изготавливаются согласно ТУ У 27.5-33600569-001:2014, проходят обязательное тестирование, имеют государственные сертификаты качества, акты испытаний в реальных условиях. Отзывы покупателей подтверждают высокую надежность и энергоэффективность всех товаров линейки.

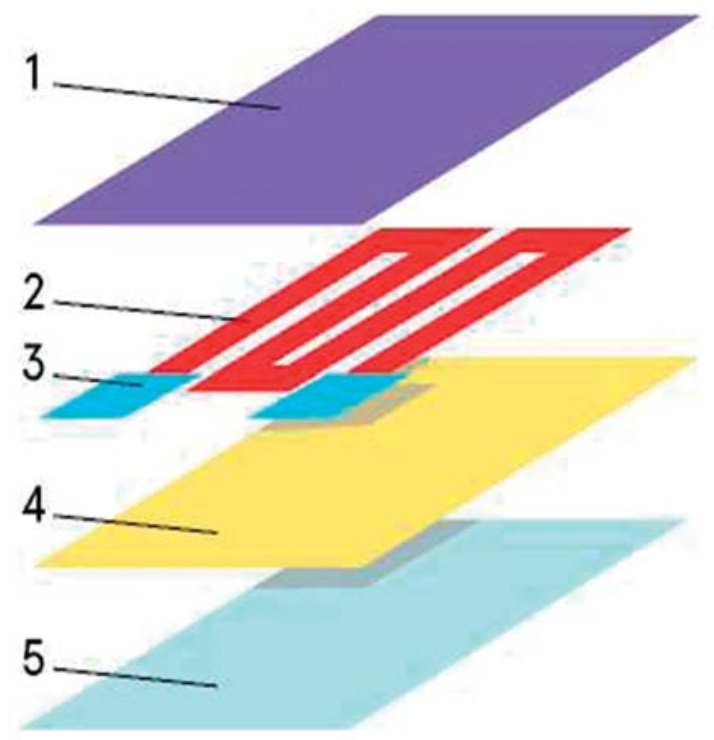

Структура ТНЭвключает в себя:

1. Защитный диэлектрический слой - паста типа ПД-1. Сопротивление изоляционного слоя не менее 50 Мом, при толщине 150 мкм.

2. Пленочная дорожка из резистивной пасты типа ПРН. Удельное поверхностное сопротивление пленки 0,05-50 Ом/см2, температурный коэффициент сопротивления (TKC) - положительный.

3. Контактная паста типа ПК. Удельное поверхностное сопротивление 0,01-0,050 Ом/см2, прочность сцепления с подложкой не менее 50 кг/см2.

4. Диэлектрическая паста типа ПД-2. Сопротивление изоляционного слоя не менее 50 Мом. При толщине 150 мкм напряжение пробоя составляет не менее $1250 \mathrm{~B}$.

5. Металлическая подложка типа 04X17, 08X17, 20X13, 15X25Т либо керамическая подложка типа BK-94, BK-96.

Данная технология была изобретена несколько десятилетий назад, но не нашла широкого применения в виду высокой себестоимости. Причина в том, что пасты токопроводящие мировых производителей, применяемые в производстве толстопленочных нагревателей, имеют в своем составе драгоценные материалы (серебро, палладий, рутений, золото).

Особенность нагревательных элементов производства ООО «Агромат-Декор» состоит в том, что для них был разработан состав токопроводящих паст без использования драгоценных металлов (на основе боридов никеля), что позволило сделать толстопленочные нагревательные элементы доступными для использования не только в промышленном, но и в бытовом тепловом оборудовании.

\section{Отрасли эффективного}

применения нагревателей

\section{1. Пищевая промышленность:}

- кухонные электрические промышленные и бытовые плиты (конфорки) для пунктов общественного питания, для домашнего пользования;

- жарочные духовые пекарские электрические шкафы, печи электрические для пиццы, варочные электрические баки (котлы для варки фарша), водонагреватели для кипячения воды, мармиты (линии раздачи пищи с подогревом), жарочные поверхности (электрические сковороды большого диаметра до 740мм), электрические грили, фритюрницы (для варки пирожков, картофеля, чебуреков), тостеры, электрические вафельницы.

2. Коммунальное хозяйство и жилищное строительство:

- устройства обогрева жилых и вспомогательных помещений: конвекторы, калориферы, обогреватели, электрические котлы, бойлеры.

3. Строительная индустрия:

- воздухонагреватели и калориферы передвижные, сушилки и сушильные пушки направленного действия, радиационные инфракрасные нагреватели местные и направленные;

- у устройства для резки пластиковых труб большого диаметра;

- устройства обогрева пропарочных камер и формовочных столов ЖБИ.

4. Аграрная промышленность и сельское хозяйство:

- сушильные установки малой (бытовые) и большой (промышленные) производительности для сушки сыпучих, овощей, фруктов и дикорастущих трав, воздухонагреватели и калориферы, инкубаторы, обогрев животноводческих и птицеферм, нагрев пищевой и технической воды проточный и накопительный.

5. Деревообрабатывающая и мебельная промышленность:

- сушка пиломатериалов, воздухонагреватели, сушильные камеры после лакокрасочных покрытий, инфракрасная сушка мебельных элементов, нагрев больших пресс-форм и плит.

\section{6. Упаковочная промышленность:}

термопластавтоматы, устройства по нанесению рисунка на пленки, устройства по сварке упаковочных пленок и производство пластиковой упаковки пищевых продуктов.

7. Химическая промышленность и производство пластмасс:

обогрев пресс-форм, проточный и накопительный нагрев растворов и воды, бесконтактный нагрев реакторов до $400{ }^{\circ} \mathrm{C}$, бесконтактный нагрев емкостей в т. ч. с агрессивными средами, прокаливание сыпучих материалов, сушильные шкафы и сушильные установки, нагрев пленочных материалов при дублировании и перед прессованием, нагрев плит. 


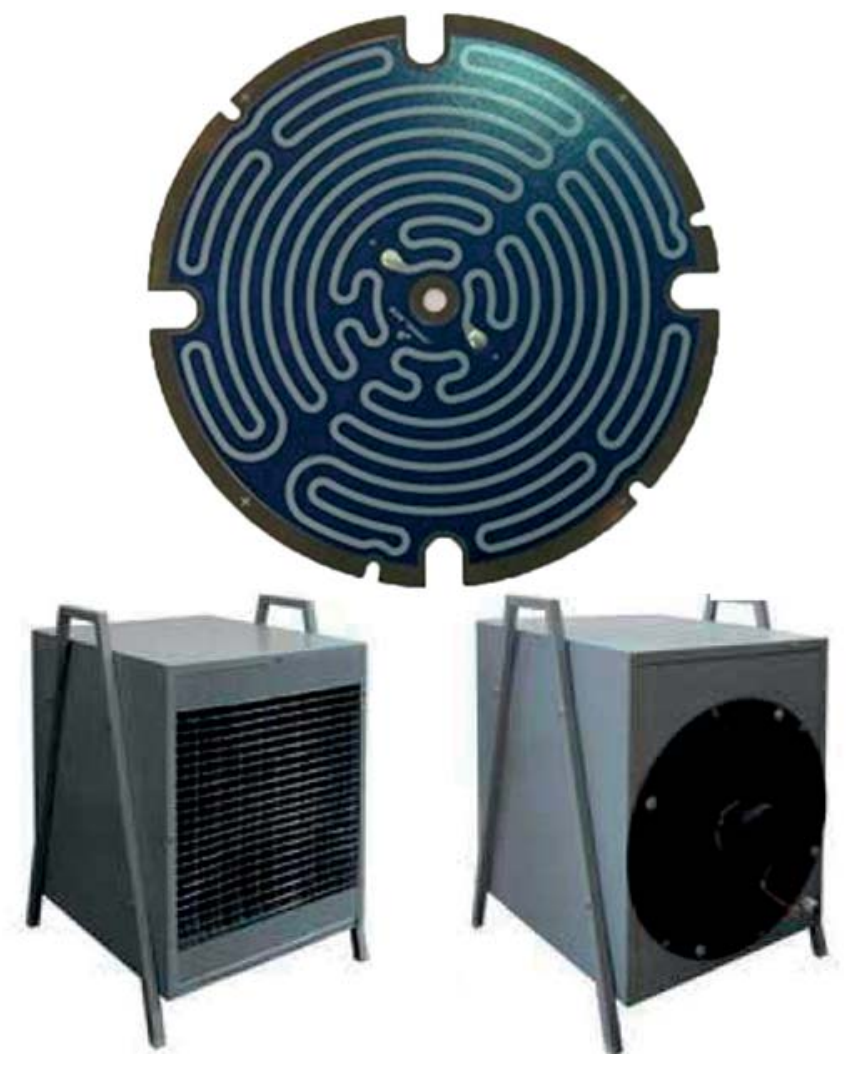

Тепловая эффективность ТНЭ

Тепловую эффективность ТНЭ рассмотрим на примере электрических воздухонагревателей (калориферов).

Для нагрева воздуха в системах воздушного отопления, вентиляции, сушилках и т.д. давно применяются промышленные теплообменники - аппараты, предназначенные для сообщения тепла вторичному теплоносителю (воздушному потоку) за счет отвода его от первичного теплоносителя.

Первичными теплоносителями обычно служили: водяной пар, горячая вода, продукты горения топлива, поэтому применение воздушного отопления ограничивалось необходимостью наличия развитой системы получения и транспортировки первичного теплоносителя, а это полностью исключало применение воздушных нагревателей на строящихся и пусковых объектах, а также в не производственной сфере: мастерских, гаражах, складах, торговых точках, в бытовых помещениях.

Применение электрических нагревателей позволило создание компактных, мобильных электрических воздухонагревателей (калориферов и конвекторов) в широком диапазоне теплопроизводительности от маломощных бытовых конвекторов до мощных производственных калориферов.

Как известно эффективность калорифера зависит от температуры теплоносителя, а применение элетронагревателей позволяет значительно ее повысить [1] .

Конструкции современных электрокалориферов в большинстве своем основаны на обдуве воздушным потоком пучка трубчатых электронагревателей (ТЭНов); при этом осуществляется конвективный теплообмен между движущимся воздухом и поверхностью нагревателя.

Количество тепла переданное воздушному потоку определяется уравнением теплопередачи [1]:

$$
\mathrm{Q}=\mathrm{a} \Delta \mathrm{tF} \dot{\mathrm{k}} \mathrm{\kappa} \text { } ж / \mathrm{u}
$$

$\mathrm{a}$ - средний коэффициент теплопередачи, $\mathrm{BT} / \mathrm{m}^{2} \cdot{ }^{\circ} \mathrm{C}$

$\Delta \mathrm{t}$ - средний температурный напор (средняя разница температур между теплоносителями), ${ }^{\circ} \mathrm{C}$

$\mathrm{F}$ - поверхность теплообмена, ${ }^{2}$

ท́ - < I коэффициент учитывающий потери тепла аппаратом в окружающую среду

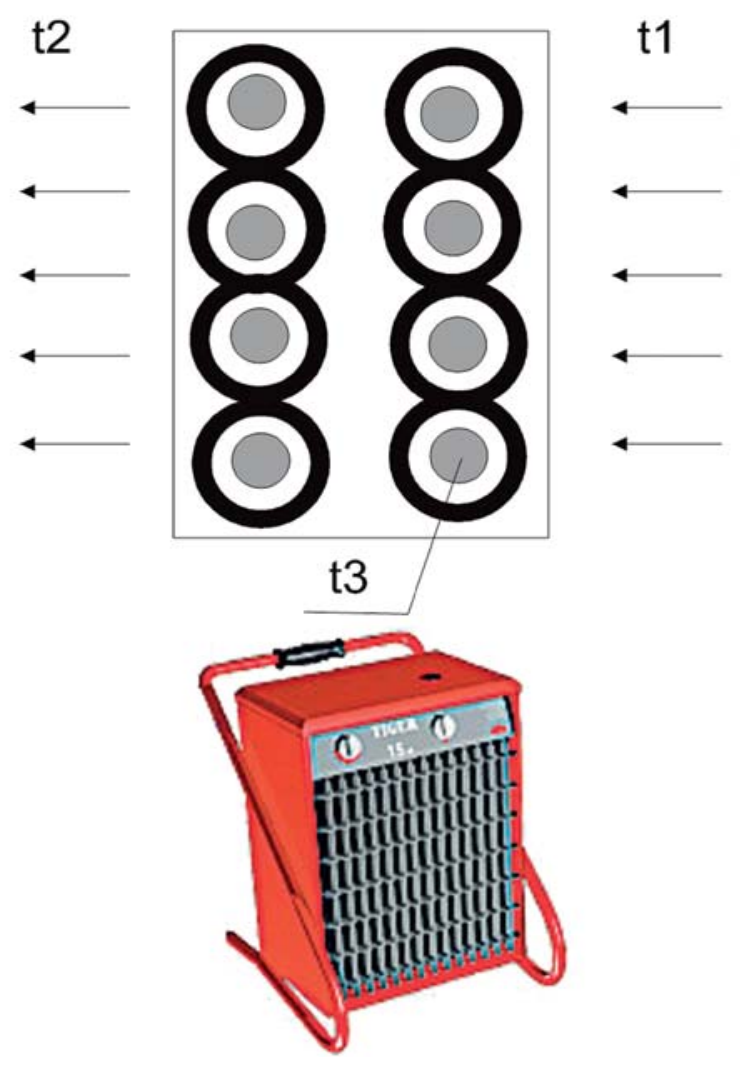

Рис. 1. Калорифер на основе ТЭНов

Как видно из формулы (1) теплообъем прямо пропорционален $\mathrm{F}$ (поверхности нагревателя).

Поверхностью ТЭНа является цилиндрическая поверхность трубки, а увеличение ее диаметра связано с увеличением толщины слоя электроизоляции, которая резко повышает термическое сопротивление, поэтому средний диаметр ТЭНа находится в пределах 12мм. Для увеличения поверхности в воздушных калориферах применяются «оребренные» ТЭНы, которые в 1,4 раза дороже, но увеличивают эффективную поверхность приблизительно в 2,5 раза.

Рассмотрим электрокалориферы с плоскими толстопленочными электронагревателями ТНЭ [2-3].

Для сравнения принимаем два одинаковых условных калорифера.

Калорифер на основе ТЭНов - Рис. 1, и на ТНЭ - Рис. 2.

$\mathrm{t}_{1} ; \mathrm{t}^{\prime}$ - температура воздуха на входе,

$\mathrm{t}_{2} ; \mathrm{t}_{2}^{\prime}$ - температура воздуха на выходе,

$\mathrm{t}_{3} ; \mathrm{t}_{3}^{\prime}$ - температура поверхности нагревателя.

Из уравнения теплового баланса количество тепла переданного воздуху [1]:

$\mathrm{q}_{1}=\mathrm{v}_{1}^{*} \mathrm{Cv} *\left(\mathrm{t}_{2}-\mathrm{t}_{1}\right)$

$\mathrm{q}_{1}^{\prime}=\mathrm{v}_{1}^{\prime *} \mathrm{Cv}^{\prime *}\left(\mathrm{t}_{2}^{\prime}-\mathrm{t}_{1}^{\prime}\right)$

$\mathrm{V}_{1}, \mathrm{~V}_{1}^{\prime}$ - количество воздуха, $\mathrm{m}^{3} / 4$

$\mathrm{C} v$ - объемная теплоемкость воздуха ккал/ $\mathrm{m}^{3}{ }^{\circ} \mathrm{C}$ (формула 1)

$\mathrm{q}_{1}=\mathrm{Q} ; \mathrm{q}_{1}^{\prime}=\mathrm{Q}_{1}^{\prime}$

следовательно:

$\mathrm{q}_{1} / \mathrm{q}_{1}^{\prime}=\mathrm{Q}_{1} / \mathrm{Q}^{\prime}=\mathrm{v}_{1} \mathrm{Cv}\left(\mathrm{t}_{2}-\mathrm{t}_{1}\right) / \mathrm{v}_{1}^{\prime} \mathrm{Cv}^{\prime}\left(\mathrm{t}_{2}^{\prime}-\mathrm{t}_{1}^{\prime}\right)=$

$=a_{1} \Delta$ tMFMń $_{1} / a_{1}^{\prime} \Delta t_{1}^{\prime} F_{1}^{\prime} n_{1}^{\prime}$

Учитывая, что коэффициент теплопередачи а в основном зависит от скорости воздушного потока w, а по условиям сравнения $\mathrm{w}^{\prime} \mathrm{w}^{\prime}$, то для упрощения можно принять $\mathrm{a}_{1}=\mathrm{a}_{1}^{\prime}$, $\mathrm{t}_{1}=\mathrm{t}^{\prime}$ 


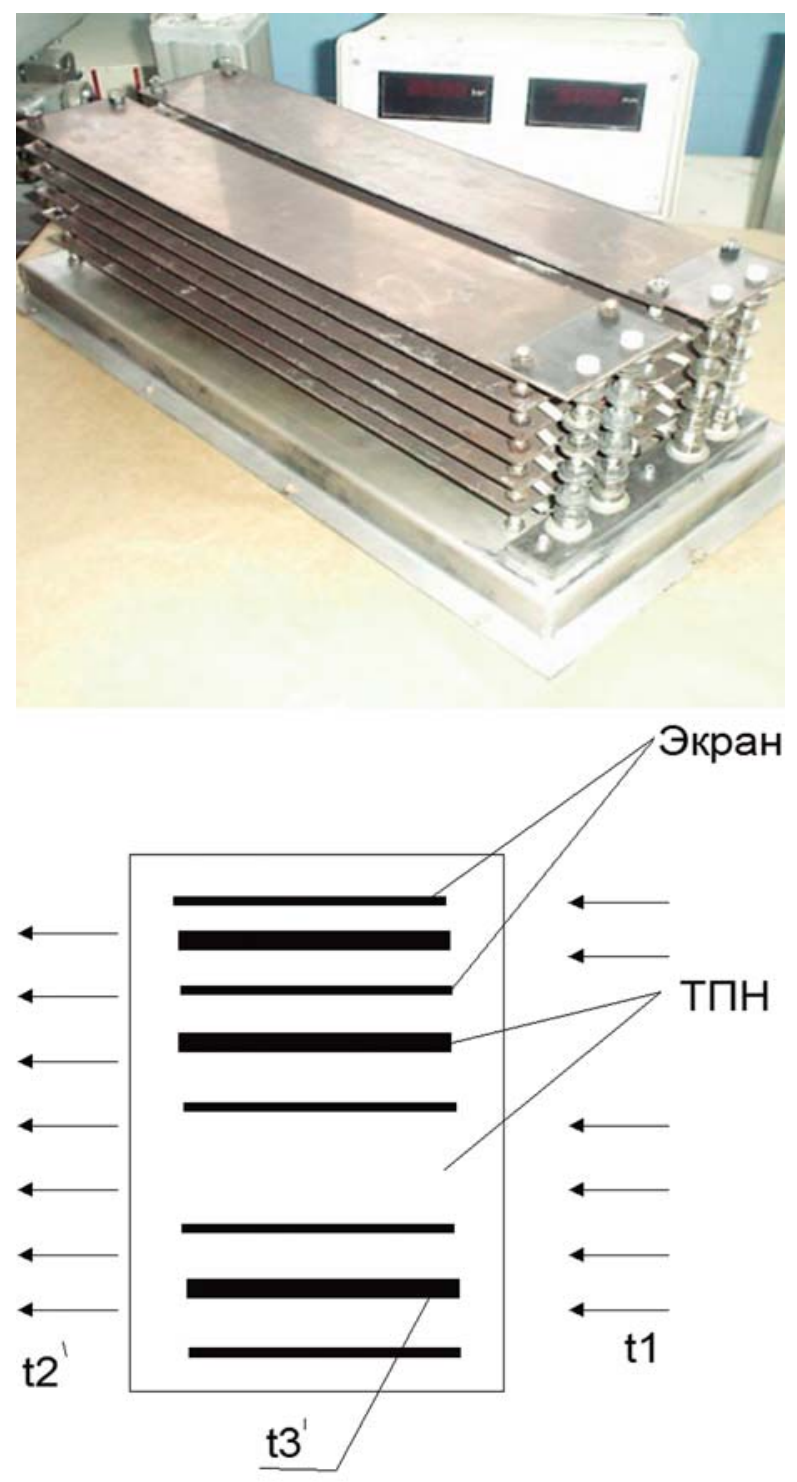

Рис. 2. Блок на ТНЭ на 20Квт, габариты 470×170×180мм

$\mathrm{q}_{1} / \mathrm{q}_{1}^{\prime}=\mathrm{Q}_{1} / \mathrm{Q}_{1}^{\prime}=\mathrm{v}_{1}\left(\mathrm{t}_{2}-\mathrm{t}_{1}\right) / \mathrm{v}_{1}^{\prime}\left(\mathrm{t}_{2}^{\prime}-\mathrm{t}_{1}^{\prime}\right)=$

$=\Delta \mathrm{t}_{1} F_{1} \eta_{1} / \Delta \mathrm{t}_{1}^{\prime} \mathrm{F}_{1}^{\prime} \eta_{1}^{\prime}=\Delta \mathrm{t}_{1} \eta_{1} / \Delta \mathrm{t}_{1}^{\prime} \mathfrak{n}_{1}^{\prime}$

На рис.1 установлено 8 шт. оребреных ТЭНов диаметром 12 мм и длинной L

$\mathrm{F}_{1}=(1,2 \mathrm{PL}) 0,5^{*} 8=76 \mathrm{~L} \mathrm{cM}^{2}$

На рис. 2 - установлено 4 нагревателя ТНЭ шириной $75 \mathrm{Mm}$, толщиной 3 мм и длиной L. Полная поверхность пластины:

$$
F_{1}^{\prime}=\left(75^{*} 2+0,2 * 7,5\right) L^{*} 4=78 \mathrm{~L} \mathrm{~cm}^{2}
$$

Равенство поверхностей соблюдается, т.е. $\mathrm{F}_{1}=\mathrm{F}_{1}^{\prime}$

Количество тепла переданное воздуху зависит от температурного напора $\Delta t$, а при заданным по условиям эксплуатации температурам воздуха $\mathrm{t}_{1}$ и $\mathrm{t}_{2}$ величина $\Delta \mathrm{t}$ зависит только от температуры поверхности нагревателя [1], т.е. чем выше $t_{3}$ тем эффективней работа воздухонагревателя, однако на повышение температуры нагревателя существует ряд ограничений и практически она определяется в пределах $300-400^{\circ} \mathrm{C}$.

При таких температурах часть внутренней энергии вещества превращается в энергию излучения, а теплообмен осуществляется переносом излучения и его поглощения другим веществом.

Тепловые расчеты теплообменных аппаратов показывают, что доля расхода энергии первичного теплоно- сителя (электроэнергии) на излучение составляет при $300{ }^{\circ} \mathrm{C}$ - $30 \%$, а при $400{ }^{\circ} \mathrm{C}$ до $50 \%$.

К сожалению воздух, как и другие 2-х атомные газы, излучение не поглощает.

Для использования энергии излучения, благодаря плоской форме нагревателя, между нагревателями устанавливаются экраны, которые представляют собой простые металлические пластины параллельные с плоскостями нагревателей [2-3]

Из теории теплообмена излучением известно [1], что если между двумя плоскопараллельными серыми поверхностями установлен тонкий экран, т.е. при условии равных степенях черноты поверхностей, количество тепла переданное экрану составляет $\mathrm{Q}_{3}=\mathrm{Q}_{\text {изл. }}$.

За счет полученной энергии температура поверхности экрана повышается и экран, как самостоятельная поверхность нагрева, принимает участие в конвективном теплообмене, возвращая полученной количество тепла воздуху.

Если теперь принять для сравнения среднюю температуру поверхности нагревателя $\mathrm{t}_{3}=350^{\circ} \mathrm{C}$, то количество тепла излучением составляет

$\mathrm{Q}_{\text {изл. }}=0,4 \mathrm{Q}$, а $\mathrm{Q} э=0,2 \mathrm{Q}$,

следовательно $\mathrm{Q}_{1}=\mathrm{Q}$ и $\mathrm{Q}_{1}^{\prime}=\mathrm{Q}+\mathrm{Q}_{\ni}=1,2 \mathrm{Q}$.

Расход электроэнергии пропорционален расходу тепла

$\left(\mathrm{N}=\mathrm{K}^{*} \mathrm{Q} / \mathrm{n}\right)$, откуда $\mathrm{N}_{1} / \mathrm{N}_{1}^{\prime}=\mathrm{Q}_{1} / \mathrm{Q}_{1}^{\prime}=\mathrm{Q} / 1,2 \mathrm{Q} ; \mathrm{N}_{1}^{\prime}=0,8 \mathrm{~N}_{1}$

Т.е. применение нагревателей ТПН с экранами позволяет в среднем уменьшить расход электроэнергии на $20 \%$.

Анализируем соотношение (3)

$\mathrm{v}_{1}\left(\mathrm{t}_{2}-\mathrm{t}_{1}\right) / \mathrm{v}_{1}^{\prime}\left(\mathrm{t}_{2}^{\prime}-\mathrm{t}_{1}^{\prime}\right)=\Delta \mathrm{t}_{1} \mathrm{n}_{1} / \Delta \mathrm{t}_{1} \mathrm{n}^{\prime} \mathbf{1}^{\prime}=1 / 1,2$

При заданном количестве воздуха $\left(\mathrm{V}_{1}=\mathrm{V}_{1}^{\prime}\right)$ - температуру воздуха на выходе из калорифера можно получить больше, т.к. t2́ $>t_{2}$;

При одинаковой температуре $\mathrm{t}_{2}=\mathrm{t}_{2}^{\prime}$ и $\mathrm{t}_{1}=\mathrm{t}_{1}^{\prime}$ можно получить в 1,2 раза больше теплого воздуха.

Из равенства $\Delta \mathrm{t}^{\prime} \eta^{\eta} i^{\prime}=1,2 \Delta \mathrm{t}_{1} \eta_{1}$ следует

$n_{1}^{\prime}>n_{1}^{\prime} ; \Delta \mathrm{t}_{1}>\Delta \mathrm{t}_{1}^{\prime} \rightarrow \mathrm{t}_{3}>\mathrm{t}_{3}^{\prime}$

\section{Выводы:}

Применение толстопленочных плоских электронагревателей для нагрева воздуха в калориферах и конвекторах позволяет:

1. Снизить расход электроэнергии на $20 \%$

2. Уменьшить (по сравнению с ребристыми ТЭНами) количество нагревателей в 2 раза

3. При эквивалентном потреблении энергии увеличить производительность

4. Снизить температуру поверхности нагревателя

5. Снизить потери тепла в окружающую среду

6. Уменьшить стоимость калорифера

7. Создавать компактные, мобильные, калориферы, конвекторы, сушилки, тепловые пушки, тепловые завесы, тепловентиляторы.

\section{Литература:}

1. Крутов В.И. редактор. Теплотех-ника. Учебник, 1986 год, 431 стр, С. 112-114.

2. Гребенкина В.Г., Доброер В.С., Панов Л.И., Тризна Ю.П., Толстопленочная микроэлек-троника, 247 стр. С. 68-72.

3. Hascard, M., Pitt, K., Thick-film Technology and Applications, Electrochemical Publications LTD, 1997, ISBN 0901150355 . 